\title{
The Difficulties of Achieving Technology Transfer: Issues of Absorptive Capacity
}

\author{
Nadia Selmi \\ Sciences économiques et membre de l'unité de recherche Economie Monétaire et Financière, \\ Faculté des Sciences Economiques et de Gestion de Tunis, Tunisie
}

Correspondence should be addressed to: Nadia Selmi; selminadia1@gmail.com

Received 9 January 2013; Accepted 8 June 2013; Published 23 October 2013

Academic Editor: Raouf Jaziri

Copyright (C) 2013 Nadia Selmi. Distributed under Creative Commons CC-BY 3.0

\begin{abstract}
This article aims to elucidate theoretically the problematic dealing with the constraints of the success of technology transfer process to developing countries through synthesizing the main theoretical approaches. Numerous and important are barriers to implementation. They are dependent on several factors ranging from initial level of development of the receiving economy, the nature of the imported technology, the market structure, the state of competition. However, despite the size of these barriers to entry, it is obvious that the knowledge imparted should be properly absorbed by the receiving economy. This implies the ability of firms to learn and master imported technologies- which requires prerequisites in terms of human capital, basic skills, capital outlay required for the activity of R\&D; as well as economic and social fundamentals of the host country for the proper handling of knowledge. This set of prerequisites identifies absorptive capacity which all developing countries wishing to optimize the transfer of technology should bring.
\end{abstract}

Keywords: Absorptive capacity, developing countries, learning, technology transfer.

\section{Introduction}

The issue of technology transfer and the conditions attached to it has continued to ignite interest in the last few years. Recent theoretical developments indicate that the economic competitiveness of a country and its ability to integrate the world market is forged over the years by the presence of technologies were they produced or imported as in the case of developing countries that interest us in this essay.

To reach this technological achievement, the way is long and strewn with obstacles of all kinds. Indeed, when we approach the themes of novelty and transfer, the risks and difficulties are numerous and persistent. The process of technology transfer is-in fact- neither simple nor systematic. It is far from being reduced to a brief relationship transmitter / receiver of knowledge. It is a complex, multi-actor and follows a number of factors and conditions that determine its success.

We propose, in the context of this paper, to present a theoretical synthesis of barriers to the technology transfer implementation and the catching up that result through the different approaches, and determine the key to the success of this transfer; the absorptive capacity. 


\section{The Difficulties of Achieving Technology Transfer:}

By approaching the issue of technology transfer in one of its most delicate parts, particularly the constraints to its implementation, Abramovitz (1986) had the merit of introducing a differentiation between the effective potential of the catching up and the achievement. Enrolling in the same lineage, other trials have suggested distinguishing among the factors representing constraints on access to those constituting implementation ones (Bellone 1997). Access barriers reveal, on the one hand in how the importation of foreign technology depends on the initial level of development of the economy in terms of know-how to use the new technology transferred, and raise the issue of unavailability of other complementary inputs that might overwhelm the adoption of imported technologies on the other hand. However, these studies have failed to consider the issue of market power structures. Indeed, the intensity of existing competition and the concentration levels relating to each sector define the nature of the constraints of the access to technology according to companies' specific targets. The entrance of the technology may be, in fact, autonomous or dependent according to whether it is initiated by competitors or dictated by the owners of companies enjoying strong competitive positions like phase change technology itself and its degree of adaptability to the requirements of the local market.

Being necessary, these conditions are not sufficient for all the success of the technology transfer process. It is further to consider the implementation issue by discussing the ways in which the adjustment of the productive structure toward the technology imported influences the dynamics of economic growth.

The endogenous growth models, explaining the origin of the long-term growth, have attempted to elucidate this issue and the extent to which the growth of a small open economy can be boosted by imports of capital goods incorporating advanced technologies of the leading countries. The pioneering work in this area belongs to Grossman and Helpman (1994) who have modeled endogenous technological progress resulting from the importance of the quantity of intermediate goods produced and used in the economy.

The new trend of endogenous innovation models focus on the internal rate of technological progress, to make a truly endogenous source of growth. Indeed, these models attempt to establish the positive impact of capital goods importation on growth. Note that in these models, the growth rate is closely linked to the extent of funds allocated to innovation activity, the degree to which new technologies are transferred and acquired as well as the temporal perspective innovators themselves. Thus, technology transfer is somewhat the result of monopoly power held by the innovative agents and the degree of interaction with innovations acquired from the host countries. But empirical studies have revealed precisely the non-obviousness for these economies- in their first stage of industrialization- to combine a strategy to develop domestic technological activity with a foreign technology appeal. Thus, are the economies of developing countries trapped to their own technological backwardness? Does their inability impede access to externalities behind growth? Therefore, the explanation of the conditional nature of technological catchup is not simply motivated by the inability of some countries to access, effectively, to the most advanced technologies. Indeed, it is the irregularity of the response of the economy in terms of receptor adaptation and management of knowledge acquired and the impact of this action on the conversion of the industrial and technological development of the internal economy that determine the success or the failure of the technological upgrading process.

The problem then acquires a new content in that the impact of the leading countries' technological progress does not always generate benefits in terms of technology development process of the receiving country and therefore the restructuring of 
its production system. The first elements of answers are found in the growth mechanism nature in the receiver economy on the one hand and the nature of imported technologies on the other.

As to the question of the imported technology selection, Dosi (1984) suggests that the market does not evaluate the technology directly; it operates, rather, as a selection device. By extensions to the Nelson and Winter visions (1977) holding the economic environment as a determinant of selection, technology is retained considering the degree of response to market needs. It is worth noting the threat exerted by some technologies on the long-term growth potential of an economy, despite their contribution to the growth of total factor productivity. Such findings would result in the establishment of a proactive policy guiding the choice of imported technologies.

An implementation of the work of Simon (1960) has attempted, through the exploitation of its canonical approach of decision making, to provide some answers to this question of the technology transfer selection. Discarding the hypothesis of the uniqueness of the optimum, Simon found that the decision is a cognitive process as complex and as recurring situations in which it must be developed. Such a process generally escapes the optimization calculations of how divergent empirical reality. Thus, the selection process technology transfer must follow a specific protocol that begins with the identification of the problems. This first phase, involves a perfect information detention about the state of technology, the changing markets, the scope of the firm's capital level, the expected benefits, the regulatory and institutional framework... However, it is not always true in reality that the information system performs its task in a timely manner: the information is not always available and easily accessible. This delay in obtaining the information can often skew the results in terms of identifying problems.

The second phase relates to the modeling which the aim is structuring the data collected to determine the range of the possible solutions and actions in terms of technology selection. This phase involves the use of computers and the manipulation of specific software, which is not clear for the majority of the decision makers who do not have extraordinary knowledge in computer science. Reappears once again the problem of the developing countries delay might block their technological upgrading.

The third phase consists of an assessment of the technology transfer modalities leading to the final decision to adopt. It seems a priori simple to execution, but it assumes the relevance and consistency of the implementation of subsequent phases insofar as the proposed alternatives should be adequate and effective. The constraints mentioned above could therefore lead to incongruous and inappropriate selection of the technology to import. Moreover, assuming that the technology selected is relevant and appropriate, it does not mean that it is unchanging and constant. Its application is subject to the requirements and ongoing changes in the economic environment, which calls for a continuous iteration throughout the decision-making process. Again, are the developing countries in an adequate position to ensure the correct continuity of the diverticulum? Do they have enough skills able to interact properly with the environment and ensure the necessary feedback?

Arise then the shortcomings of this systemic approach, particularly as in practice the analysis of the genesis and the modalities for the transfer and upgradingespecially over the long term- clearly escape the conceptual framework of this approach. 
At this level, only one conclusion seems to be relevant: the technology transfer and the resulting catching-up- assumed to be derived on- are not an automatic process, even when the access constraints do not challenge a priori, the incentive to opt for the import of technology.

The approaches summarized above are insufficient to contain all the constraints that determine the success of technology transfer. Empirical reality has shown that its deficiencies are underlying the neglect to take into account the ability of the economy to absorb and master properly imported technology. Note however that Verspagen (1993) has attached particular importance to the policies implemented by the governments of backward countries to support efforts to learning and mastery of the knowledge transferred. But Verspagen was relatively short in defining components prior to catching up and convergence in developing countries. It was Abramovitz (1994b), who provided these prerequisites by calling them social capacity and technological capacity. Abramovitz presented these prerequisites as the auspices of the success of the catching-up process between the economies of the receiving countries on the one hand and the economy's leader ones on the other hand. Indeed, Abramovitz (1994) and then Hanson and Henrekson (1996) have tried to estimate the effects of capacity on the process of catching up, and they succeeded to confirm the theoretical predictions. However, their contributions have not attempted to determine the impact of these prerequisites on the transfer process itself. This is the contribution of the absorptive capacity concept, which had a first merit to present a more explicit synthesization of these prerequisites abandoning the Abramovitz's distinction between social and technological capacities. This concept also sets the clear goal of conditioning the success of the technology transfer process, before moving to catching issues and transition.

\section{The Absorptive Capacity in Emerging Countries, a Necessary Condition for the Success of the Technology Transfer Process}

Building on the lessons summarized above showing the difficulty of achieving technology transfer, it is relevant to analyze the real potential of developing economies to invest in this long process. Indeed, to ensure the foundation for a successful operation of the technology transfer, the receiving countries must carry fundamentals, necessary for learning and good management of knowledge.

While considering a variety of factors including the quality of socio-economic organization of the receiving country, particularly its geo-economic context and the strength of its human capital, these fundamentals include skills available in the country Home and essential to the use and operation of the technology, the assurance of the maintenance and improvement of management practices. They also consist of outlays necessary for the promotion of learning like links within the national system of knowledge.

This set of factors that affect the proper functioning and optimization of the process of technology transfer and that make a country absorb more efficiently the foreign technology than another one, define the concept of absorptive capacity that we propose to analyze under this section.

\section{The Concept of Absorptive Capacity}

\section{Definition of the Concept}

The concept of absorptive capacity has been used for the first time in order to solve problems related to organizational phenomena spanning multiple levels of analysis including organizational learning (Huber, 1991; Kim, 1998), the industrial economy (Cockburn and Hunderson 1998), resource-based (Lane \& Lubatkin, 1998) and dynamic capabilities perspectives (Mowery, Oxley \& Silverman, 1996). 
In 1990, Cohen and Levinthal define absorptive capacity as "the ability to recognize the value of new information, assimilate it, and apply it to commercial [...]" (Cohen and Levinthal, 1990, p.128). It is about an edifice of routines and organizational processes through which the business or the system acquires, assimilates, transforms and uses the knowledge to build a dynamic organizational capacity (Zahra and George, 2002). Zahra and George (2002) consolidate the findings of the multidimensionality of the concept as well as the variability of these dimensions. Lane and Lubatkin (1998) use the same components as Cohen and Levinthal (1990) in their essay on the prerequisites for organizations to learn and learn from others. For Van Den Bosch et al., (2005), absorptive capacity is approached by three main components: the ability to recognize the value of external knowledge, assimilate it, and apply it to commercial resolutions (p. 280). It is the ability of an organization to learn and solve problems (Kim, 1998). A multitude of studies have shown the importance of absorptive capacity in enhancing the performance of the organization (Cohen and Levinthal, 1990; Levinson and Asahi, 1995, Mowery et al., 1996, Mukherjee et al., 2000). In the same way, the absorption capacity is recognized as a foundation of technical learning within the organization (Kedia and Bhagat, 1988; Veuglers and Cassiman, 1999).

Despite the discrepancies in the definition of this concept, as some authors have defined it as the firm's responsiveness to changes in technology (Kedia and Bhagat, 1988) while others have assimilated to the 'ability of the firm to master new technologies (Koza and Lewin, 1998), there was, however, a theoretical consensus on the role of absorptive capacity in determining the entitlement of the firm to manage knowledge and technology transfer.

In final, three synthetic definitions were used to converge on some points and differ on others in the sense that each one illustrates a particular dimension.
Cohen and Levinthal (1990) define it as the ability of the firm to evaluate, assess and use the new technology. According to Mowery and Oxley (1995), it is the set of skills or expertise needed to manage components implicit knowledge transferred and editing. According to Kim (1997, ab, 1998) it is the ability to study and solve problems.

This multidimensional concept of absorptive capacity requires to be treated, a new conceptualization to elucidate each dimension and realize their reach.

In compiling the definitions cited above, it appears that the absorptive capacity is a set of organizational routines and processes by which the firm acquires, assimilates, transforms and exploits new knowledge transferred in the goal of developing a dynamic organizational ability. It is certain that these four faculties refer respectively to the four dimensions of absorptive capacity and play different but complementary roles on the illustration of the importance of the latter on the organization of the firm.

\section{The Dimensions of Absorptive Capacity}

According to Eisenhardt and Martin (2000), although these skills (defined above) have complementarities and convergences, they show a disparity that offers to the firm fundamentals to build different kinds of comparative advantages. They refer, as Teece et al., (1997) to processes and organizational routines rather than strategic or empowered, thereby reconfiguring business resources with the aim of adapting to new rules markets. They focus on the specific processes underpinning dynamic capabilities, including whether the process of creating access to new knowledge, or the process of developing a new product. Dynamic capabilities reside for Eisenhart and Martin (2000) on identifiable routines specific to certain essential functions such as the creation and ownership of knowledge, or the ability to form alliances or partnerships. Here we will discuss each of these skills and the way in which they 
are combined to build the absorptive capacity.

\section{* The Acquisition}

It corresponds to the ability of the firm to identify and acquire the knowledge and technology necessary for its external development. According to Lane and Lubatkin (1998), Zahra and George (2002), it is the ability to recognize, value and acquire external knowledge essential to business operations. The efforts invested in the acquisition process technology are conditioned by three determinants: the intensity, speed and direction. The intensity and the speed of the firm efforts are largely responsible for the ability to acquire new knowledge. However, there is a threshold at this speed since the learning cycles cannot be reduced easily like some vital resources to build the absorptive capacity that are not readily assembled (Clark \& Fujimoto, 1991). The direction of the accumulation of knowledge is also indicative of the path that follows the company to obtain them. In the same vein, Welsch, Liao and Stoica (2001) combine the acquisition of knowledge to a generator for the organization. The acquisition depends on previous investments in R \& D, the previous knowledge.

\section{* The Assimilation}

It refers to the process whereby the firm analyzes, processes, interprets and understands the knowledge and the technology transferred from abroad (Kim, 1997 a, b; Szulanski, 1996). It is the ability of the firm to absorb external knowledge, it is routines and processes that allow it to understand, analyze and interpret information from external sources (Zahra and George, 2002). These technologies are likely to incorporate heuristic processes that differ significantly from those used by the firm, and causing a delay in the understanding of new knowledge (Leonard-Barton 1995). Moreover, knowledge is transferred to a specific welldefined context which may prevent its assimilation by the receiving firm (Szulanski, 1996). It should be noted, to match, that understanding is particularly difficult when the transferred technology requires specific qualifications that are not always available within the host firm (Teece, 1981).

\section{* The Processing}

It refers to the ability of the firm to implement methods to promote synergy between existing knowledge and the acquired and assimilated one. The transformation is likely to change the character of knowledge through the creation which takes place when a situation or idea is perceived in two different settings. Thus, it is seen as the ability of the firm to identify two sets of information, at first sight incongruous, and combine them to produce a new diagram representing the processing capacity. Such a capacity that emerges from this creation process sculpts a new vision of the firm (McGrath \& MacMillan, 2000) and stimulates entrepreneurial actions (Smith and DeGregorio, 2002).

Therefore, this processing capacity generates new perceptions, facilitates the identification of opportunities and changes the way in which the firm assesses its competitive environment. It is also among these disparate activities, that we witness the genesis of new skills.

\section{* The Operation}

We have first to draw the attention that in the definition of the absorptive capacity by Cohen and Levinthal, the emphasis is on the application of technology by incorporating operating as a dimension of this capability. The operation is in such a way that it allows the company to develop, extend and take advantage of the existing skills on the one hand and creating new skills by integrating the acquired and transformed knowledge on the other hand. Such a mechanism allows the firm to obtain and use technology and incorporate it into its production process. These are, according to Zahra and George (2002), routines allowing the firm to refine, extend, and influence the existing skills or create new knowledge by incorporating the transformed knowledge (Zahra and George, 
2002). These provide a measure by the use of the number of patents or the new product announcements.

\section{The Components of the Absorption Capacity}

We focus- at this level- on how the dimensions mentioned above are combined. We distinguish for this purpose, two components: "the potential capacity" described by the size of the acquisition and assimilation, and "the realized capacity" designed by the dimensions of the transformation and the exploitation.

"The potential capacity" accommodates the firm to acquire and assimilate the foreign technology (Lane \& Lubatkin, 1998) without guaranteeing its operation as "the realized capacity" is closely correlated with the ability of the transformation and the exploitation discussed above. These two components have distinct but complementary roles to the extent that they coexist and obey a necessary but not sufficient condition to improve the performance of the firm. For example, a firm cannot exploit an unlearned technology or it may acquire and assimilate technology without the means to transform and exploit it. Thus, a strong "potential capacity" does not necessarily imply a performance optimization; it is only in turning new knowledge and exploiting that the company can improve its competitiveness.

So, it is obvious that the competitiveness and efficiency of a firm become heavily dependent on its ability to properly handle these two components of absorptive capacity. Baker, Miner and Eesley (....) assume that firms develop absorptive capacity greatly higher to their operating capacity. They emphasize that some of them have an extreme expertise in understanding the knowledge that has been transmitted, but are unable to realize and exploit their assets and to extract value.

This confirms the imperative to distinguish between the ability to acquire and assimilate knowledge (the potential capacity) and those to transform and exploit (the realized capacity) and predisposition to manage these two components.

Indeed, this separation is essential to understand their respective contributions in determining the comparative advantage. First, such a distinction helps explain why some firms are more efficient than others on the use of their absorptive capacity. Despite the importance of the "potential capacity", it is the "realized capacity" that determines the performance improvement of a firm. It also reflects the different ways in which these two components contribute to the construction of the competitive advantage of a firm.

In addition, there are both endogenous and exogenous factors that guide the impact of those two components highlighting the role of managerial skills in the optimization of their use. Moreover, the distinction can observe and examine the variability of the processes followed by organisms while developing their skills.

\section{Factors Affecting the Absorptive Capacity}

The absorptive capacity is subject to changes driven by different internal and external factors (Daghfous, 2004). Internal factors consist of the previous knowledge base (we emphasize the dependence of the company to its prior history), the autonomous absorptive capacity referring to the necessary investment in the absorptive capacity which leads to the development of new knowledge and the detection of external signals, the level of education and academic degrees earned by employees which will evaluate the possibility of integrating new knowledge, the contribution of specialized players, the organizational structure and organizational culture which define other ways to organize the communication between the actors, the size of the firm, as well as the investment in $\mathrm{R} \& \mathrm{D}$ and human resource management. As for external factors, they incorporate environmental of the external knowledge and the position in the knowledge network. 
Lin \& al., (2002) scrutinize the essential elements of the absorptive capacity by referring to its implications for the effective technology transfer. The authors clearly mark the relevant symbiosis between the absorptive capacity factors such as the transfer channels, cumulatively learning, and resources in R \& D. Tsai (2001) draws an optical network type and focuses on the importance in terms of innovation and efficiency of a suitable positioning of the structure in this network. Although they manage to conquer the new knowledge developed by other organizations, but the absorption capacity and the ability of the facsimile that determine ultimately the continuity and the success of the process.

In a more detailed ideation than the $\mathrm{R} \& \mathrm{D}$ one, there are many works that have emphasized the interaction of the different elements with the absorptive capacity: the intellectual predispositions staff and their inspiration (Minbaeva and Michailova, 2004), the historical knowledge (Lane, Salk and Lyles, 2001), the wisdom and consistency of knowledge, the consistency of the organizational structures, and the shared research communities (Lane and Lubatkin, 1998). In addition, studies are insufficient to detect the impact of the absorptive capacity in the context of an international expansion and to explain how companies procure, handle and accumulate knowledge in international operations (Rhee, 2005).

The construction of the ability of a firm to invent requires an exploratory learning type (McGrath, 2001). When adaptation requires innovation and the creation of varieties, the exploration is vital (March, 1991). Thus, Van Den Bosch et al., (1999) distinguish three ranges of the absorption of knowledge: its effectiveness, its scope and its flexibility (p. 552), the authors argue that it is the ability of organizations to identify, assimilate and exploit knowledge from an optical-based costs and the exploitation of economies of scale that determines the efficiency of knowledge absorption; the extent testifies to the scope of the component knowledge that the organization operates, and finally the flexibility refers to the ability of the organization to acquire additional knowledge and rebuild the existing one. Van Den Bosch et al., (1999, p. 552) consider that the flexibility and the extent of the knowledge absorption are eagerly combined with exploration type adaptations (March, 1991), the configuration of the knowledge of the company, while the effectiveness is related to the adaptation of such operations.

\section{The Contribution of the Absorptive Capacity}

The role of absorptive capacity has been extensively discussed in the theoretical literature mainly through the work of Cohen and Levinthal (1989.1990) and Patrick Guillaumont (1971.1985 Volume 2 ). We will review the main contributions of these two approaches.

\section{A-Genesis and Notional Positioning}

Patrick Guillaumont (1971.1985 Volume 2) states that "the notion of absorptive capacity (...) applies to the capital from all sources, both internally and externally: it expresses a set of limits on the transformation of capital available or real capital mobilized useful development." The author discerns as "technical limitations" (lack of infrastructure, lack of skills ...) and "political boundaries" (setting threshold dependence foreign) whose combination circumscribed "a general capacity of absorption, maximum useful investment "(Ibid).

In addition, Guillaumont addresses the problem by distinguishing two micro and macro optical in that it incorporates the analysis of absorptive capacity. Enrolling in a microeconomic level, it refers to "maximum feasible investment without its rate of return becoming zero." We note well as the presence of a limited capacity is manifested by a steep decline in the profitability curve representing the volume of investment, therefore, a redefinition of the capacity may be possible "with reference to a certain threshold below which, the rate of return must not fall "(Guillaumont 1985, Volume 2, 88). According to the macroeconomic approach, absorptive capacity is considered as "the 
maximum feasible investment without the fact its growth rate stops rising" (Ibid, 88).

According to Cohen and Levinthal (1989.1990), the intrusion of the absorptive capacity notion adheres to the theme of technological catch-up, where the preponderance of the role of $R \& D$ expenditures is recorded. Therefore, according to these authors, if the budget for research and development ostensibly leads to innovations, it also displays the ability of firms to identify, acquire and advance knowledge from the environment. This is what they call learning or absorptive capacity of firms. Note that this approach is rather micro because it punctuates the technological competitiveness of firms.

However, the concept of absorptive capacity largely exceeds the predictions of the two conceptualizations discussed above. Surely K.Ohzawa and H.Rosovsky (1973) were the pioneers in introducing the concept of social capability to elucidate the growth rate of Japan during the 1950s and 1960s. This notion of social capability "covers a wide range of issues, including the performance of the economic, educational, financial and political, which all influence the rate of growth of the country" (Criscuolo and Narula, 2002.2).

It should be noted, moreover, that the concept of absorptive capacity is in line with the theory of endogenous growth. Indeed, with reference to the question of the impact of FDI on the host economy, the concept of absorptive capacity can be illustrated as an instrument, the capital vocation of which is to isolate the analysis of the FDI impact from the field of the neoclassical growth theory and present it as an analysis of the quantitative accumulation of factors in order to integrate it into the field of the endogenous growth theory to appear as an analysis of the accumulation qualitative factors.

The suitability of the former is greatly reduced because of diminishing returns and the assumption of exogeneity of technological development paralyzing thresholds development related to countries and condemning any opportunity for adjustment of the least developed. The relevance of the latter is further affirmed after winning the limit of diminishing returns by the efficiency with which these factors of production are developed, which will take shape by the total factor productivity. This qualitative component of growth is highly dependent on the absorption capacity.

\section{B-Human Capital Pillar of the Absorptive Capacity}

Cohen and Levinthal (1990, P128) state that "the evaluation and use of the external knowledge - to a large extent- tribute of the level of the prior related knowledge." They adopt the assumption that the learning capacity of a country is motivated by its initial endowment of human capital. GS Becker (1962.1975) has developed this concept relative to aspects relating to education, training and health of individuals. Human capital embodied intangible capital given the confusion of the individual with his knowledge, his skills, his health and his values. Note that education, with all the dimensions it encompasses, is a key factor of human capital. The significant attention ascribed derives from the fact that its impact on society is theoretically indisputable and its assessment is technically executable. The analysis based on primary, secondary and higher education distinguishes the different profiles. Indeed, empirical work rallying the relationship between education and growth have argued that the growth of OECD countries mainly leans on a higher level of education (Petrakis and Stamatkis, 2002), the developing countries one is attributed in addition to primary and secondary levels (Self and Grabowski, 2004).

\section{The Organizational Problematic in the Absorptive Capacity}

It is clear, as has been stated above, that human capital, characteristic of tacit information and the ability to learn, is the axis of the absorptive capacity. However, it is interesting to speculate at this level of its organization in the national economy. The performance of this organization is closely 
linked to its propensity to release human capital so that its learning ability is usable at the highest level.

Note from the outset that among organizations (designed in the broadest sense) where human capital is enclosed including universities, companies, research centers ... the firm is the most organization discoursed by the literature economy. The problem is erected to two organizational levels: intra-organizational and interorganizational level.

\section{The Intra-Organizational Level}

The first observation to indicate is that the concept of absorptive capacity has resulted in a challenge to the usual differentiation between active and specific standardized assets derived from the theory of transaction costs (Williamson, 1985). This theory states that in case of repeatable transactions, which involve specific assets in an uncertain environment characterized by the opportunism and the timing of individuals and their narrow rationality, the best method to ensure the efficient performance would be the internalization. This is the main idea of the eclectic theory that clarifies the problem of the multinational firms (Dunning, 1981).

Therefore, in the transaction costs model, the transfer of the assets from a governance structure to another is accommodating because of the preservation of the inherent quality of the asset (the quality of human capital). In case its operation generates a lower level of performance, this is purely due to the choice of bad governance.

However, in a context promoting productive human capital factor, the theory of transaction costs does not deal with the choice of the governance strategy. Such a shortcoming derives from the uniqueness of its goal revolving around solving the issue of boundaries of the firm considering the tacit assumption that all things are equal. This gives it a purely instrumental character, mainly dedicated to discern between the possible forms of governance by letting the relevant issue to address realistic changes that the passage of governance by the market governance the company may, in particular, to infer. It removes the threat of underdevelopment of the assets, including close links which are subject to reduction qualitatively (Foss, 1994). Indeed, it is imperative to ask whether the new firm has organizational and technological capabilities to support the empowering path development of the internalized human capital. This is the contribution of multinationalisation theory (Buckley, 1995; Casson, 1996). Buckley argues, in this regard, that "the internalization approach has failed to develop its implications regarding relationships within the firm."

Therefore, the static conception of human capital provided by the theory of transactions is not compatible with its dynamic nature. It confronts the imperativeness of experimentation and collective memory as an insurance construction skill (Foss, 1996; Loasby, 1998a, 1998b). This perspective owes its origin to the evolutionary perspective of the firm (Nilson and Winter, 1982). Involved by the learning capacity of the human capital of the firm and likened the confused learning potential of the latter to provide organizational remedies driven by the skills theory. In this way, the firm was not structured around a septic vision of human nature-that of individual opportunism (Williamson) - but around an optimistic perception that enhances the learning potential of individuals.

Therefore, the performance and expertise of a company is the culmination of a long experimental protocol and memory using the assets of the organization in terms of intelligence, education and aptitudes of its human capital. Such allocation is partly tacit and can be distributed among the individuals in the firm, but is not switchable. The skills presumed basal offer the firm the opportunity to build a competitive advantage vis-à-vis its competitors. It would be appropriate to distinguish between reproductive skills and dynamics competencies (Christensen, 1994). According Cohendet et al., (1990, 230) reproductive skills concur with the 
notion of static routine specific to evolutionary theory; these routines are repeated and developed incrementally. Nevertheless, the dynamic skills involve modifying routines and provide a base for competitive advantage via the stimulation of the innovation and the generation of new capabilities. Consequently, reproductive skills, by their nature, conventional, and proceeding by decentralized distribution of information are only entitled to reduce costs of ownership of this information. However, in the context of a modern economy dynamics, the optics is not to restrict information costs but to build effective learning practices.

According to the theory of the firm skills, there is no company that is able to retain skills in all phases of the production cycle (Langlois and Robertson, 1995.30). Generally, the production of a final good requires a combination of skills exceeding the basal ability of individual firms. It should also draw the attention that within a firm, there are indirect skills enabling it to obtain assets under the jurisdiction of other firms (Loasby, 1998b, 149). The protagonists of the theory of the firm argue that a lot of knowledge how imperative to the success of a company resident somewhere else. They also punctuate consequently the contribution of markets regarding the accessibility of this knowledge, especially following the targeting potential players likely to be filled (Loasby, 1996.50).

\section{The Inter-Organizational Level}

The reasoning led in terms of skills highlights the hegemony of the learning process for the procurement of a competitive advantage. But such a process is not conceivable with abstraction of the connections contiguity between the local organization and imminent economic and social environment (Fujita and Thisse, 1997; Torre and Gilly, 2000).

The attention given to industrial location addresses the non-neutrality of the space in the competitive process. The irregularity efficiencies between firms in the same industry can be attributed to disparities in the areas of membership of each firm. This is why "The space almost inevitably leads to imperfect competition" (Scotchmer and Thisse, 1993, 654). His status is not exogenous, but endogenous to the extent that industrial location itself leads to internal benefits.

Marshall (1890 and 1919) defines the notion of industrial district which is the general concept describing the benefits of the geographic concentration of economic activities. According to Becattini (1992, 36 and 37) "industrial district is a socioterritorial entity characterized by the active presence of a community of people and a population of firms in a geographical and historical context. In the district, unlike what happens in other types of environments such as manufacturing towns, it tends to be perfect osmosis between local communities and businesses. "Such harmony is realized via two assets "as those relating to human resources collected and those from the technical interdependence of activities created. (...) There is no need to separate and Marshall also presents them in a single movement "(Gaffard and Romani, 1990.173).

The idea is that the agglomeration of human resources boosts the transmission and consolidation of skills. "The industry secrets cease to be secret, they are almost in the air, and the children learn many of them unconsciously" (Marshall 1890, 225). It is an "industrial atmosphere" supporting the faculty and consolidation of skills which materializes a genuine cultural process (Gaffard and Romani 1990, 174). The inherent advantage, granted by the interaction of technical activities is at this mass boldly specialized equipment and the level of standardization and specialization resulting from the continuous interaction between inventors and equipment users (1990.174-175 Gaffard and Romani). These authors interrogate, namely, about the possibility that all productive activities of an industrial district form a single composite production process- whose time of learning, development and the construction of a production capacity- are the only specific scope. Finally, the 
industrial district as an efficient market works to amass a multitude of professional dynamics. Professional mobility of workers does not condemn its specialization, as it continues to incorporate public good that Marshall refers to as industrial atmosphere. (Becattini, 1992.36).

Therefore, the concept of industrial district perfectly elucidates the allocation of substantial collective learning in determining and maintaining the competitive position of a firm and realizes its complementarity with the learning internal to the firm- a source of new skills. A multinational firm wishing to subscribe to human capital resources which the local firm has is adjoined to a double learning. The question that arises here, and reflects a serious problem is that-s if this multinational, by internalizing, is able to effectively lean the internal learning with all the risk of damaging the quality of external learning that represents the change in the governance structure.

Like any other type of economic and social environment, the industrial district has spillover effects that go through financial and technological externalities (Scitovsky, 1954). Fujita and Thisse (1997.43) argue that "pecuniary externalities refer to the benefits of economic interactions realized through the usual mechanisms of the market, while technological externalities deal with interaction effects outside the markets, directly affecting consumer utility or production functions of companies"

We conclude that it is the intensity of technological externalities, not transiting by the market, which reveals the degree of integration of a local firm in its immediate economic environment.

\section{The Setting Models Involving the Absorptive Capacity}

The models of the absorptive capacity incorporate one or more of the following: the background of absorptive capacity, absorptive capacity and its components and the output generated.

\section{The Van den Bosch, Volberda and de Boer Mode (1999)}

Van den Bosch \& al., (1999) discern three types of determinants preambular to the absorptive capacity and two types of organizational outputs (the absorptive capacity being considered as a moderating variable). The characteristics of the absorptive capacity include the quantity of prerequisite knowledge related to the field of knowledge transfer, and two types of determinants adapted to the context, including the organizational structure (traditional functional, matrix, networks), and multiple sets of organizational capacity related or combined (coordination capacity, formal system capacity and socialization skills) (Van den Bosch et al., 1999, p.555). These capabilities are realized by a set of organizational mechanisms such as the participation in decisions, or the routinization of practices (Jansen et al., 2005).

The model of Van den Bosch \& al., (1999) explains how the determinants related to the context and the organization can moderate the access and the use of prior knowledge. It admits two kinds of organizational outputs closely related: the creation of expectations associated with the ability to identify opportunities in the environment, and the ability to explore and exploit these new development paths.

\section{The Zahra \& George Model (2002)}

The Zahra and George model joined the same antecedent continuity: absorptive capacity / organizational outputs. The process is enriched by the inclusion of three moderating variables: triggers at the interface between the background and absorption, mechanisms of social integration between the potential absorptive capacity and the realized absorptive capacity, and the presence or absence of protective measures to curb imitation when creating products and services. 
Zahra and George (2002) showed that firms which have developed a highlyrealized absorptive capacity are able to excel in innovating and developing the new products. Those who have developed a high potential absorptive capacity will be more flexible and acclimated to rebuild their resources according to strategic issues (Zahra and George, 2002, p. 196).

\section{An Overview of the Lessons Learned from the Recent Literature on the Concept of the Absorptive Capacity}

The recent literature developed on the absorptive capacity has the merit of providing new perspectives related to the expansion of the concept (Laneet al., 2006) as those related to critical aspects of questioning models founders (Todorova and Durinsin, 2007).

\section{- $\quad$ The Lane, Koka \& Pathak model (2006)}

Lane \& al., (2006) propose to refresh the concept of absorptive capacity by reconnecting it to the network of assumptions, precursors and results. They develop a model that values the process history - absorption - results, but by refocusing on "the drivers" of the absorptive capacity, both internal and external, on the multidimensional view of absorptive capacity, and results in the long term.

- The Todorova et Durisin (2007) model : the Zahra et George model (2002) reviewed

Todorova and Durisin (2007) suggest a reconceptualization of the model of Cohen and Levinthal (1990), and detect the ambiguities and gaps in the work of Zahra and George (2002). Todorova and Durinsin (2007, p.775) reintegrate the recognition of the knowledge value as a component in the original model of Cohen and Levinthal (1990). Focusing on the learning theories, they argue that the processing component of knowledge is not the step subsequent to the assimilation of knowledge. It is rather seen as a process associated with alternative assimilation through multiple channels. This logic leads to the confusion of the potential absorptive capacity and the realized one (Zahra and George, 2002, p.192).

Todorova and Durinsin (2007, p.776) cared about the factors called contingent. The contingent factor of social integration affects not only the conversion, but also other components of absorptive capacity. Overall, the authors propose the new power relations as contingent factor. Finally, to better understand the dynamic nature of the phenomenon, the authors establish new feedback links.

\section{Conclusion}

We have tried to present a summary review explaining the process of acquiring the technology and the challenges and the conditions that are attached to the perspective of different theoretical approaches. We proceeded in a first section to the elucidation of the difficulty of achieving the technology transfer and the catch-up of the small economy by specifying constraints and conditional execution of the process.

The second section was allocated to the theoretical study of the absorption, which has been defined in the context of the first part as a set of organizational routines and the processes by which the firm acquires, assimilates, transforms and exploits the new knowledge transferred to the objective of developing a dynamic organizational capability allowing it to interact appropriately with knowledge.

It has been shown in the second part, that this absorptive capacity available to the receiving country, is responsible for the fact that the transmission of the same technological knowledge packet does not have the same effect on the productive systems of the different hosts countries and this inevitably influences the absorptive capacity through its four components, the process of catching up in emerging countries and their degree of exploitation of foreign technology. The concept of absorptive capacity is assumed as capital together as a determinant of business innovation (De jong and Freel, 2010; 
Murovec and Prodan, 2009) and competitive advantage (Teece, 2007).

\section{References}

Amesse, F. \& Cohendet, P. (2001). "Technology Transfer from the Perspective of the Knowledge-Based Economy," Research policy, 30:1459- 1478

Ayerbe-Machat, C. (2003). 'Innovation Technologique et Organisationnelle au Sein des PME Innovantes: Complémentarité des Processus, Analyse Comparative des Mécanismes de Diffusion,' XIIè conférence de l'Association Internationale de Management Stratégique, Les côtes de Carthage, Tunisie 3-6 Juin

Bellon, F. (1997). "Les Difficultés de la Réalisation du Rattrapage Technologique," Revue Economique 48 pp 409-418

Ben Abdennebi, H. (2003). 'Transfert Technologique et Processus de Rattrapage d'une Économie en Transition : Le Rôle des Capacités Sociales et Technologiques,' Thèse d'état univ Tunis El Manar FSEGT

Ben Abdennebi, H. \& Rezgui, S. (1998). "Les Effets de l'IDE sur les Systèmes d'innovation et Apprentissage," in Bellon et Gouia pp 135-145

Bloom, D. E., Canning, D. \& Sevilla, J. (2002). "Technological Diffusion, Conditional Convergence and Economic Growth," Working Paper8713 National Bureau of Economic Research, Janvier

Charpenteau, C. (2002). 'Les Processus d'acquisition de Ressources Technologiques Externes,' ADIS Université Paris Sud XI

Cohen, W. M. \& Levinthal, D. A. (1990). "Absorptive Capacity: A New Perspective on Learning and Innovation," Administrative Science Quaterly, 35(1), pp. 128-152

De Jong, J. P. J. \& Freel, M. (2010). "Absorptive Capacity and the Reach of Collaboration in High Technology Small
Firms," Research Policy, 39: 47-54. Freel, M. S.

Escribano, A., Fosfuri, A. \& Tribó, J. A. (2009). "Managing External Knowledge Flows: The Moderating Role of Absorptive Capacity," Research Policy, n³8(1), p. 96105.

Fabrizio, K. R. (2009). "Absorptive Capacity and the Search for Innovation," Research Policy, n³8(2), p. 255-267.

Huygens, M., Van Den Bosch, F. A. J., Volberda, H. W. \& Baden-Fuller, C. (2001). "Co-Evolution of Firm Capabilities and Industry Competition: Investigating the Music Industry, 1877-1997," Organization Studies, $\mathrm{n}^{\circ} 22(6)$, p. $971-1010$

Kumar, S. \& Seth, A. (2001). "Knowledge, Absorptive Capacity and the Theory of the Diversified Firm," In Academy of Management Proceedings, Nagao D (ed).Washington, D.C.; E1-E6.

Kim, S. (1990). "Technology Transfer, Technological Capability and Industrial Structure in Developing Countries," in Cicciotti et al (eds) pp 56-66

Lane, P. J., Kokka, B. R. \& Pathak, S. (2008). "The Reification of Absorptive Capacity: A Critical Review and Rejuvenation of the Concept," Academy of Management Review; vol 31 No. 4, 833-863

Liouane, N. \& Teffahi, B. (2006). 'La Diffusion Technologique par le Commerce International, le Rôle de la Capacité d'absorption,' (Etude empirique entre les pays de l'OCDE et les pays MENA)

Murovec, N. \& Prodan, I. (2009). "Absorptive Capacity, its Determinants, and Influence on Innovation Output: CrossCultural Validation of the Structural Model,“ Technovation, Dec, Volume: 29 Issue: 12 pp.859-872

Noblet, J.- P. \& Simon, E. (2010). "La Capacité d'absorption, un État de l'art," Revue Management et Avenir n³5, Mai 
Oucief, A. (2008). "Transfert de Technologie et Intégration Régionale dans la Zone Euro-Méditerranéenne: Union Européenne - Pays du Maghreb," Actes du colloqueOuverture et Emergence en Méditerranée, Octobre

Parente, S. L. (1994). "Technology Adoption, Learning by Doing and Economic Growth," Journal of economic theory, vol $63, n^{\circ} 2$

Parent, R., Roy, M. \& St-Jacques, D. (2007). "A Systems-Based Dynamic Knowledge Transfer Capacity Model," Journal of Knowledge Management, ${ }^{\circ} 11(6)$, p. 81-96.

Teece, D. J. (2007). "Explicating Dynamic Capabilities: The Nature and Microfoundations of Sustainable Enterprise Performance," Strategic Management Journal, n²8(13), p. 1319-1350.

Todorova, G. \& Durisin, B. (2007). "Absorptive Capacity: Valuing a Reconceptualization," Academy of Management Review, n³2(3), p. 774-786.

Zahra, S. A. \& George, G. (2002). "Absorptive Capacity: A Review, Reconceptualization, and Extension," Academy of Management Review, n²7 (2), p. $185-203$

Zghal, R. (2000). 'L'appropriation de la Technologie, le Savoir et le Développement,' Ecole Méditerranéenne de Développement, Le Caire 6-9 Mars

Zollo, M. \& Winter, S. G. (2002). "Deliberate Learning and the Evolution of Dynamic Capabilities," Organization Science, n¹3(3), p. 339-35 